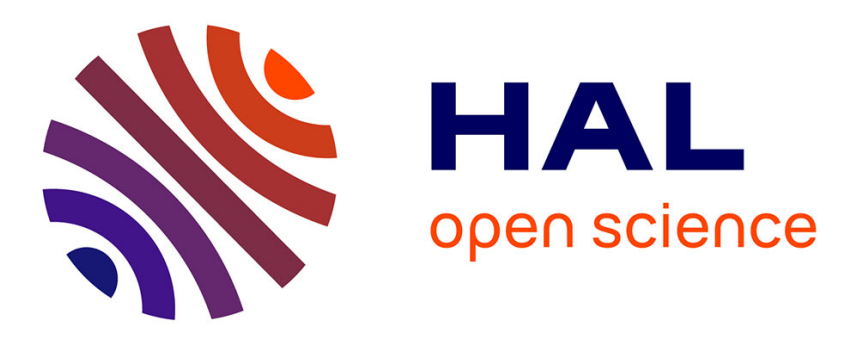

\title{
Replacement of Parts by Part Agents to Promote Reuse of Mechanical Parts
}

Hiroyuki Hiraoka, Atsushi Nagasawa, Yuki Fukumashi, Yoshinori Fukunaga

\section{To cite this version:}

Hiroyuki Hiraoka, Atsushi Nagasawa, Yuki Fukumashi, Yoshinori Fukunaga. Replacement of Parts by Part Agents to Promote Reuse of Mechanical Parts. 14th IFIP International Conference on Product Lifecycle Management (PLM), Jul 2017, Seville, Spain. pp.394-403, 10.1007/978-3-319-72905-3_35 . hal-01764196

\section{HAL Id: hal-01764196 https://hal.inria.fr/hal-01764196}

Submitted on 11 Apr 2018

HAL is a multi-disciplinary open access archive for the deposit and dissemination of scientific research documents, whether they are published or not. The documents may come from teaching and research institutions in France or abroad, or from public or private research centers.
L'archive ouverte pluridisciplinaire HAL, est destinée au dépôt et à la diffusion de documents scientifiques de niveau recherche, publiés ou non, émanant des établissements d'enseignement et de recherche français ou étrangers, des laboratoires publics ou privés.

\section{(c)(1)}

Distributed under a Creative Commons Attribution| 4.0 International License 


\title{
Replacement of parts by part agents to promote reuse of mechanical parts
}

\author{
Hiroyuki Hiraoka ${ }^{1}$, Atsushi Nagasawa ${ }^{1}$, Yuki Fukumashi ${ }^{1}$, Yoshinori Fukunaga ${ }^{1}$ \\ ${ }^{1}$ Chuo University, Tokyo, Japan \\ hiraoka@mech.chuo-u.ac.jp
}

\begin{abstract}
Replacement of parts is a crucial task for the reuse of parts. In this paper, functions of part agent we are developing that support the reuse are described. A part agent manages life cycle of a part using a network agent and an RFID tag attached on the part and generates advices for the user on the maintenance of the part in order to promote the reuse. Part agent we are developing to support the replacement has the following functions. First function is to detect deterioration of the part from its sensory data. As an example, simple 3dof manipulator is developed with modularized link structure. Part agent is assigned for each module and generates advice on its replacement. Second function is to calculate the possibility of failures of part based on causal relation among user operations and detected events. Third function is to support users to disassemble used parts. Part agent generates disassembly procedure of the part and shows it to the user using augmented reality technique. In this paper, the planned scheme for part agent to support reuse of part with these functions is described and preliminary result of the development is shown.
\end{abstract}

Keywords: Part reuse, Replace, Part agent, Life cycle

\section{$1 \quad$ Introduction}

The effective reuse of mechanical parts is important for the development of a sustainable society [1]. To realize effective part reuse, it is essential to manage individual parts over their entire life cycle because each individual part has a different reuse history. However, it is difficult for manufacturers to predict such information due to the uncontrollable and unpredictable diversity of user behavior. For factories and plants, there are various effective methods such as in the domain of reliability engineering have been developed to maintain multiple machines and equipments in shop floors. However, users in home have difficulty to apply such methods to their appliances and vehicles and to decide when their part should be replaced with which used part in the market. This is because, firstly, users have various single products to which methods to maintain multiple similar machines in a floor are difficult to apply. Secondly, most users do not have access to appropriate maintenance information on his parts and products. Based on these considerations, we propose a scheme whereby a part "manages" itself and supports user maintenance activities.

adfa, p. 1, 2011.

(C) Springer-Verlag Berlin Heidelberg 2011 
In this paper, we focus on replacement of parts and propose functions of part agent to support users to replace parts, as we consider replacement of parts is a core task in reuse of parts. It consists of two subtasks that are decision of parts to be replaced and support of user to disassemble the part. Proposed concepts and architecture of part agent's functions to support replacement of parts is described.

The concept of part agent is described in section 2. In section 3, after the issues on part replacement are described, framework of part agent to replace a part is described. Functionalities of part agent we are developing for this purpose are described in section 4 . Section 5 summarizes the paper including remaining issues.

\section{Part agent}

A part agent manages all information about its corresponding part throughout its life cycle. The proposal assumes the spread of networks and high-precision RFID technology [2]. A part agent is generated at the manufacturing phase of core parts, when an RFID tag is attached to its corresponding part. The part agent identifies the ID of the RFID tag during the part's life cycle, tracking the part through the network. We chose an RFID tag for identification because RFIDs have a higher resistance to smudge or discoloration than printed bar codes during the long period of a part's life cycle.

Fig 1 shows the conceptual scheme of the part agent. The part agent communicates with various functions within the network and collects the information needed to manage its corresponding part such as product design information, predicted deterioration of parts, logistic information, or market information. It also communicates with local functions on-site, such as sensory functions that detect the state of the part, stor-

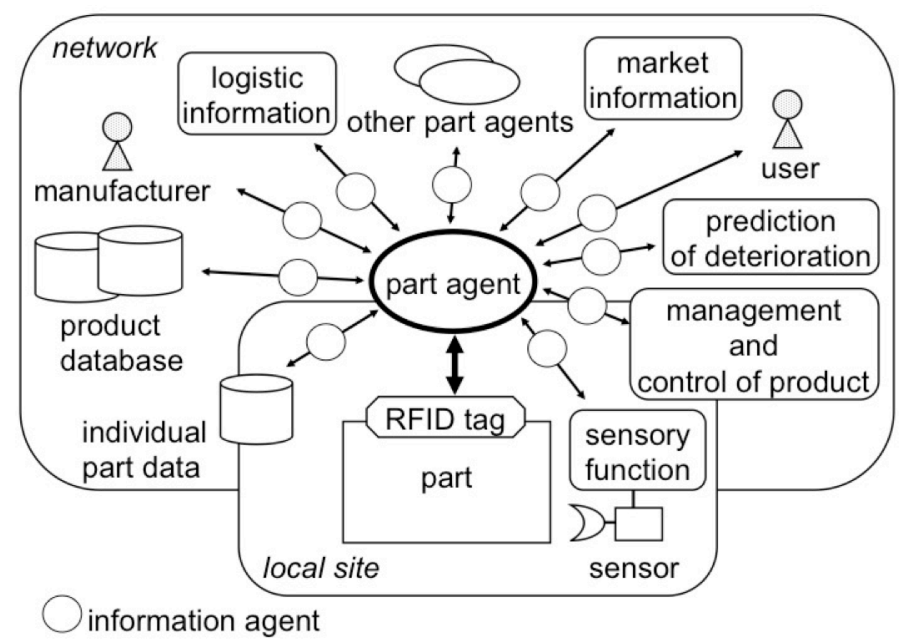

Fig.1 Conceptual schema of part agent 
age functions for individual part data, and management and control functions of the product. Communication is established using information agents that are subordinate network agents generated by the part agents.

In this paper we describe a part agent system we are developing based on this fundamental scheme to support user on replacement of part.

\section{Framework of part agent for replacement of parts}

\subsection{Replacement of parts}

Challenges in promoting reuse of parts include selection of parts to be replaced and disassembly of those parts. The decision whether a certain part should be replaced or not is made based on monitored state of the part and its diagnostics. Methodologies on condition-based maintenance and predictive maintenance of product have been developed such as $[3,4]$. In addition to detection and diagnostics of current situation of parts and products using these methods, it is better to take in consideration their expected future state by forecasting the future stages of the life cycle. Users need help on decisions on whether a part should be replaced or not and, in case of replacement, when and with which part it should be replaced.

Disassembly of a part from its assembly is necessary in order to execute the replacement of parts. Most disassembly procedures are provided in design stage of the product. However, it may not be applicable to disassemble used parts because of the degradation and deformation of fastening components over a long time. Assistance is required for disassembly operators to find alternative disassemble procedures.

To resolve these issues, we are developing functions of part agents that help users replace parts.

\subsection{Agent framework for replacement of parts}

Based on the consideration described above, we are developing a framework of part agent that supports user to replace a part as shown in Fig. 2. It consists of four components; detection of deterioration based on assembly model of the product, prediction of failures based on causal relations of probable events, prediction of part behavior based on life cycle of the part, and advice generation of replacement of the part.

Deterioration of part is important information to determine if the part should be replaced. Detection of the deterioration by part agent is described in 4.3. Possibility of failure of the part is also important for the purpose. Bayesian estimation we are developing to estimate the possibility of part failure based on causal relations of events is described in 4.2. With the information on deterioration and failure possibility, part agent foresees the future states of part based on its life cycle and evaluates current possible options as described in 4.1. Part replacement is advised if the replacement is evaluated as appropriate. Disassembly procedure of the part that is required to execute the replacement is generated as described in 4.5 . 


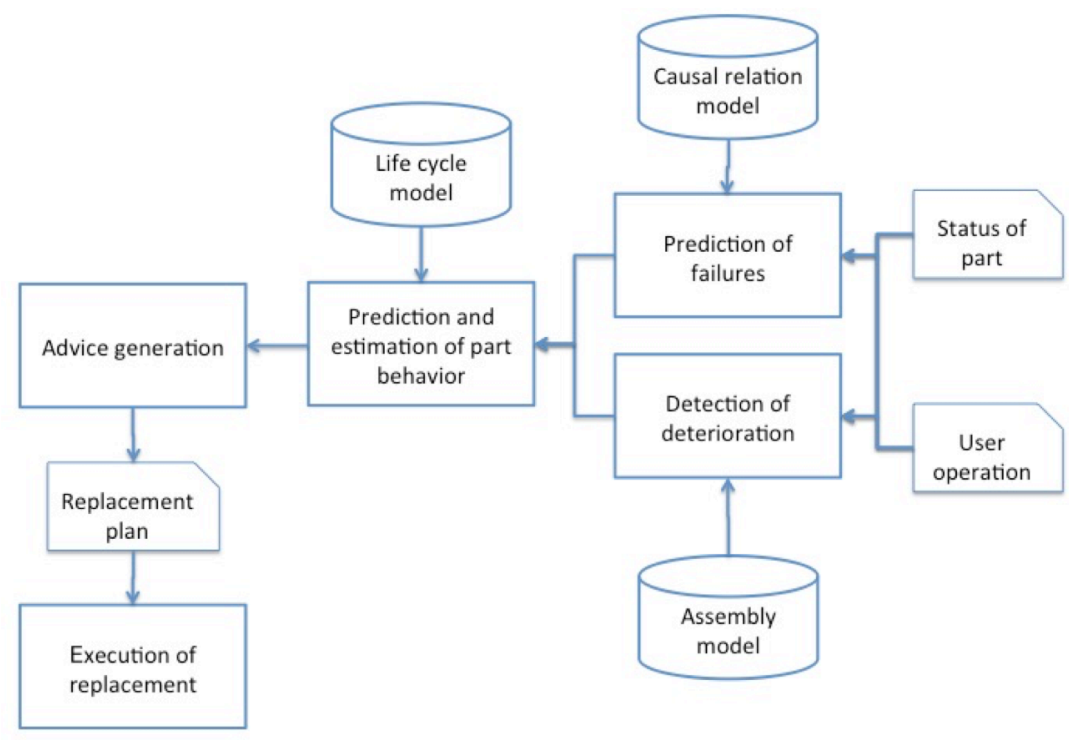

Fig. 2 Proposed framework of part agent for replacement of parts

\section{$4 \quad$ Planned functions of part agent for replacement of parts}

\subsection{Generation of advice by part agent based on life cycle model}

Fig. 3 shows a basic framework for a part agent to advise its user based on the life cycle model of a part. A life cycle model consists of life cycle stages and life cycle paths that represent transfer between them. At each time step, the part agent predicts possible states of the part in the near future, and evaluates the options of actions in order to give advice to the user [5].

A part agent expands the life cycle to evaluate every options of expanded life cycle path for several time steps in the future. Fig. 4(a) shows a simple example of the life cycle model. Circles represent life cycle stages that include produce, sell, use, repair, and dispose. Arrows depict life cycle paths. The part agent expands this life cycle of the part to represent possible changes in its life cycle over time. Fig. 4(b) shows an expanded life cycle of the part starting from the "use" stage. 
The evaluation of actions in the life cycle is based on two kinds of information. One is the possibility of failures, explained in the next section and the other is the simulated state of the part, including its environmental load, benefit, and cost. These values are estimated for every life cycle stage in the near future using the current sta-

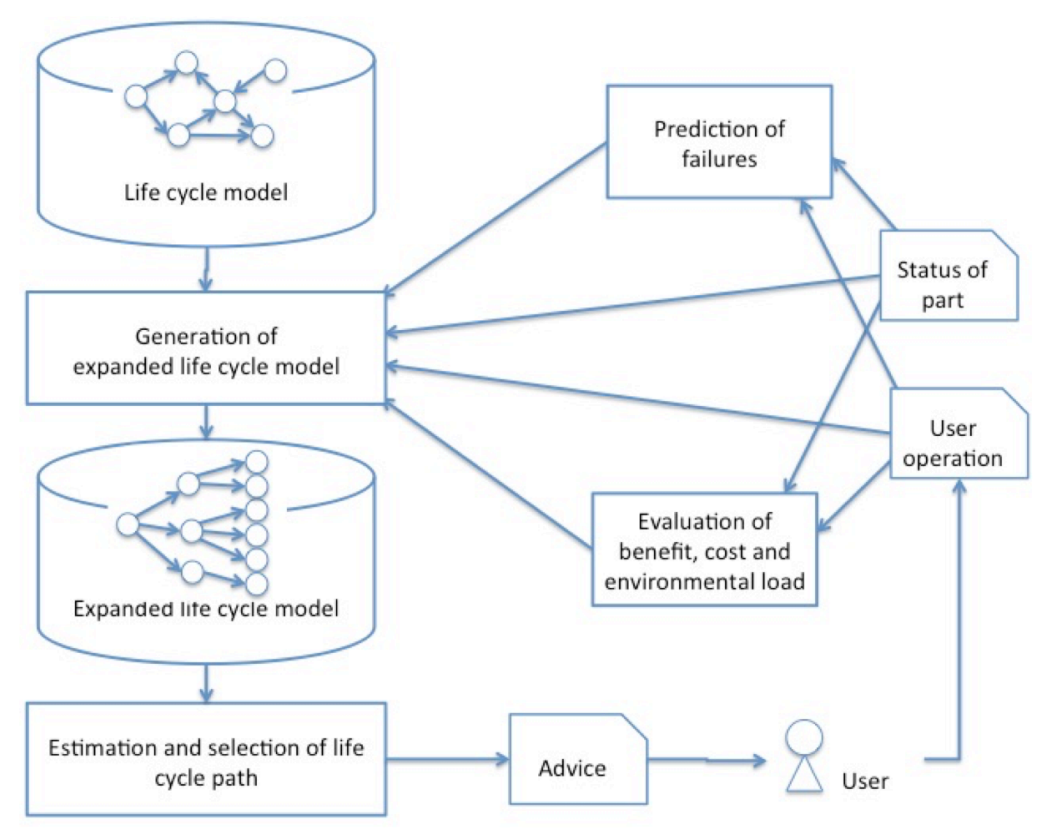

Fig. 3 Generation of advice by part agent

(a)

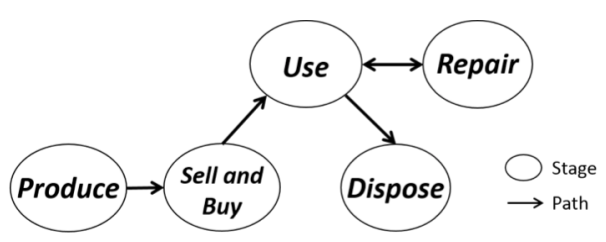

(b)

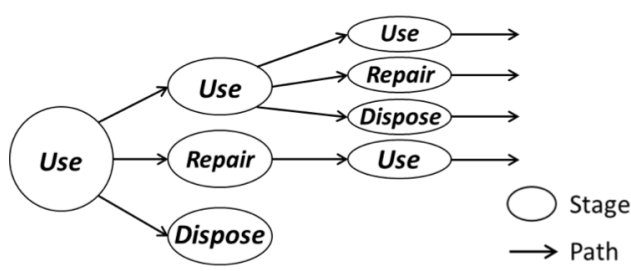

Fig. 4 Generation of advice by part agent 


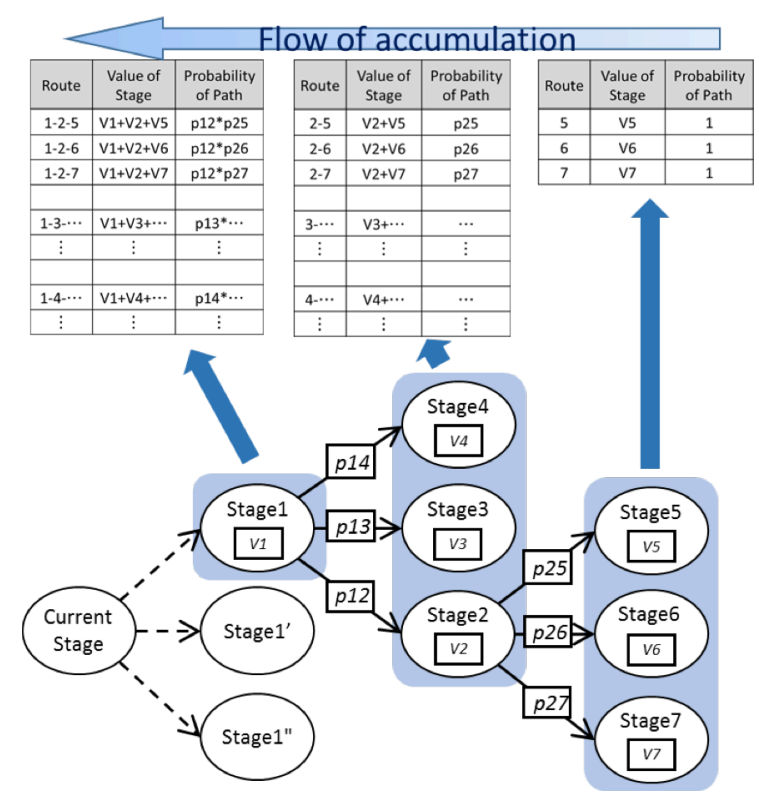

Fig. 5 Process of accumulating the values of the life cycle

tus of the part and information about its deterioration. Possibility of failures is also taken into consideration in the estimation of life cycle stage. The evaluation is performed as described below.

The expanded life cycle represents possible changes in the life cycle of the part over time. An expanded life cycle path represents a transfer from an expanded life cycle stage to another stage in one time step. Each expanded stage has values required or generated there for the step, such as cost, environmental load, and benefit. Probability is assigned to each expanded life cycle path. It represents a probability that the part agent takes that path and is estimated considering the probability of failures of the part.

Fig. 5 describes how a part agent selects the next stage using the expanded life cycle of the part. The figure shows an example situation in which the current life cycle stage shown in the left is a "Use" stage and the possible candidate stages in the next time step are Stage1, Stage1', and Stage1". A circle denotes an expanded life cycle stage with its property value such as V1, V2 and V3. An arrow denotes an expanded life cycle path with its probability such as p12, p13 and p14. To evaluate each possible candidate stage, its expected value of a property is calculated, taking into consideration the series of paths in the future. A series of stages connected with the paths is defined as a "route." The property values for the next stages and their probabilities are collected for all possible routes that could occur in the future. The expectation is then 
calculated for each route by multiplying the sum of the property values and the product of probabilities, as shown in equation (1).

$$
E V=\sum_{\text {route }}\left(\sum_{\text {stage_in_route }} V * \prod_{\text {path_in_route }} P\right)
$$

where, $\mathrm{EV}$ is the expected value of a candidate in the next stage with considering the future stages,. $\mathrm{V}$ is the sum of the property values for the stages in a route, and $\mathrm{P}$ is the accumulated probability of the paths in the route.

We apply this schema to generate advice on replacement of the part.

\subsection{Qualitative prediction of failures}

Predicting the occurrence of failure is one of the most important and the most difficult tasks. Considering its probabilistic nature, we applied a Bayesian network to the failure model that represents causal relations between the failure of the part with the operations of its user and the current status of the part [6]. The system estimates possibility of failures based on observed events such as detected status of the part, user inputs and other detected events. We have still issues to apply this scheme to practical application. One of those issues is creation of the failure model and, as a first step, we are considering a method to improve the failure model based on a library of causal relations [7].

\subsection{Detection of deterioration of modules}

Deterioration of a part affects its performance, operational cost and environmental load. Many methods and systems have been reported to detect deterioration of products. In this paper, we are developing a system, as shown in Fig. 6, to control the manipulator and to detect deterioration of part using part agent [8]. A simple robotic manipulator shown in Fig. 7 is built for a target product. A part agent is devised for each module that consists of a link and a joint. We are developing a part agent that detects deterioration of module while controlling it. When a module agent detects the level of deterioration exceeds the limit, the module agent informs the manipulator agent of the fact and it generates a plan of replacement of the module.

\subsection{Adaptive disassembly plan for replacement of part}

In order to replace a part, the part must be disassembled from its assembly. A disassembly procedure is provided that is generated at the design phase of the product. However, the predefined procedure may not be applicable for used parts that are used for a long period because of the altered materials such as rust and deformation of the part. We are developing adaptive disassembly planning system that generates multiple alternative disassembly procedures as shown in Fig. 8. Instructions for the disassembly procedure are displayed overlaid on the captured image of assembly. 
Fig. 7 shows an image of a simple assembly that is displayed with the disassembly instruction overlaid by a prototype system [9]. The system identifies the parts in the assembly using marker-based recognition technique and displays the disassembly instruction with arrow based on disassembly operations generated using assembly model.

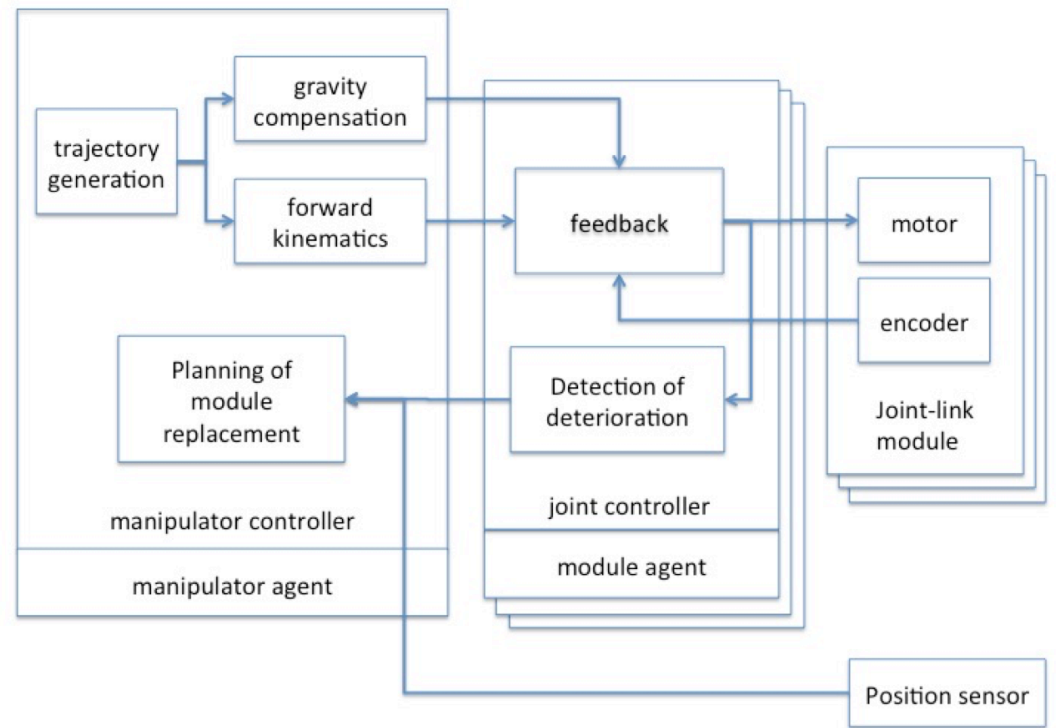

Fig. 6 Detection of deterioration for module of robot manipulator

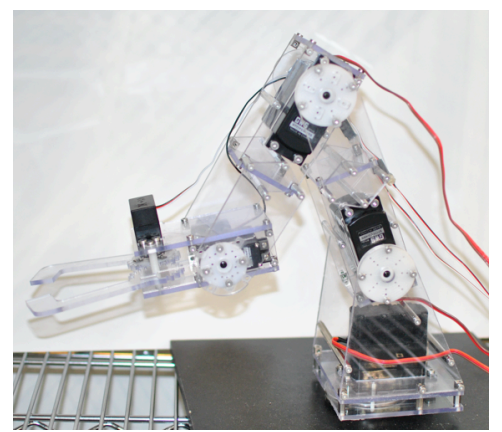

Fig. 7 A simple robotic manipulator for the experiment 


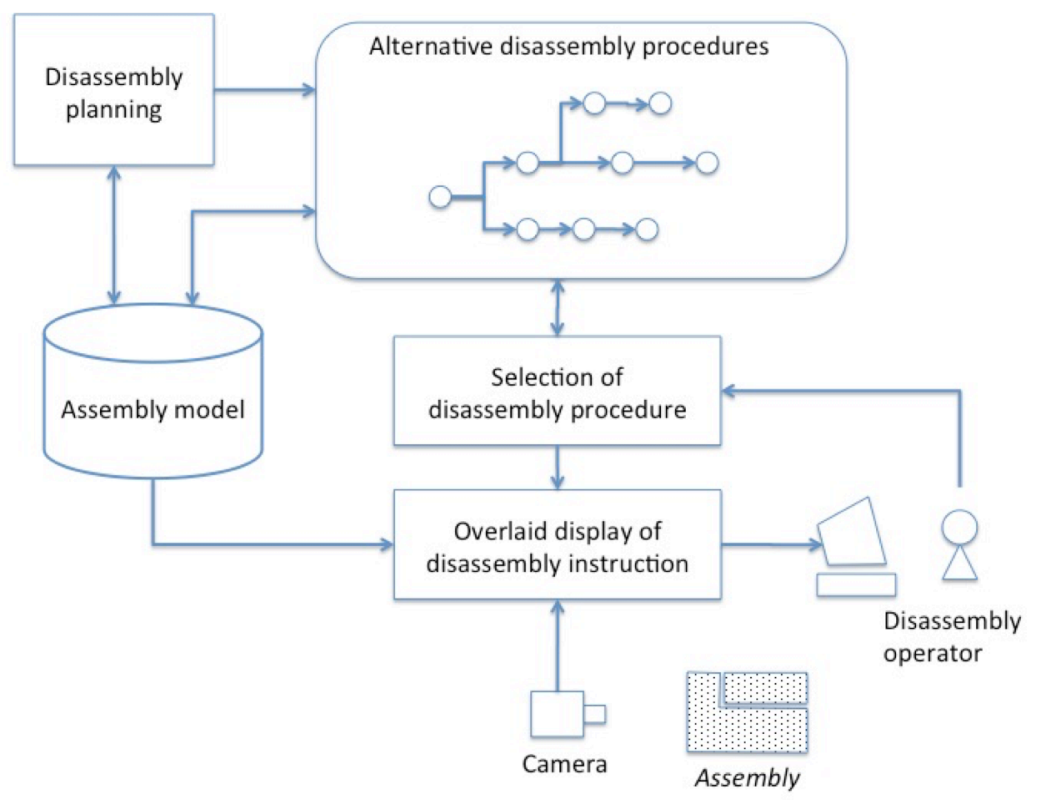

Fig. 8 Adaptive disassembly plan for replacement of part

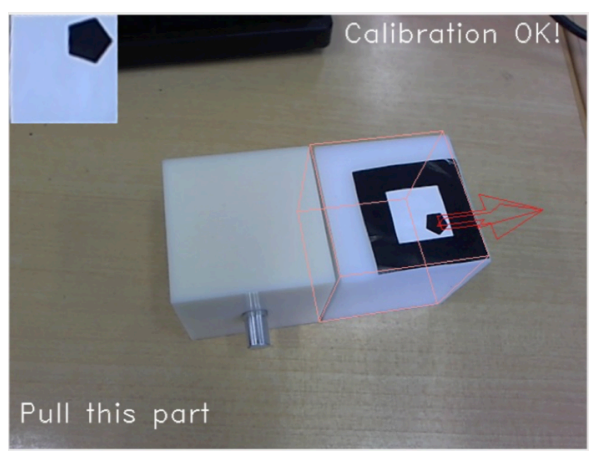

Fig. 9 Overlaid display of disassembly instruction for a simple assembly

\section{Conclusion}

Replacement of parts is an essential task for executing reuse of parts. In this paper, we propose functions of part agent that gives the user advices on replacement of parts considering the future state in the life cycle. 
The function creates the advice by calculating the expected future TPI of the part based on its deterioration and failure probability estimated by Bayesian network. A simulation of the system is made to evaluate its effectiveness and its first result is reported. We expect flexible maintenance will be achieved using part agents with this function for the cases where predetermined maintenance cannot be applied.

We are developing a part agent system to support the replacement of parts based on the proposed scheme described in this paper. Elaboration of the system is still required and experiments is necessary to validate the effectiveness of the system.

Acknowledgements. This work was supported by JSPS KAKENHI Grant Number 24560165.

\section{References}

1. Hauschild, M., Jeswiet, J. Alting, L.: From Life Cycle Assessment to Sustainable Production: Status and Perspectives. Annals of CIRP, vol. 54, no. 2, 535-555 (2005)

2. Borriello, G.: RFID: Tagging the World. Communications of the ACM, Vol. 44, No. 9: 34-37 (2005)

3. Hashemian, H.M., Bean, W.C.,:State-of-the-Art Predictive Maintenance Techniques, IEEE Trans. on Instrumentation and Measurement, vol.60, no.10, 3480-3492 (2011)

4. Jin, C., Ompusunggu, A.P., Liu, Z., Ardakani, H.D., Petre, F., Lee, J.: A Vibration-Based Approach for Stator Winding Fault Diagnosis of Induction Motors: Application of Envelope Analysis. Annual Conference of the Prognostics and Health Management Society 2014 (2014)

5. Nanjo, K., Yamamori, Y., Yokoki, Y., Sakamoto, Y., Hiraoka, H.: Maintenance decisions of part agent based on failure probability of a part using Bayesian estimation, The 22nd CIRP conference on Life Cycle Engineering, Sydney, (2015)

6. Hiraoka, H., Ueno, T., Kato, K., Ookawa, H.,, Arita, K.,, Nanjo, K., Kawaharada, H.: Part Agent Advice for Promoting Reuse of the Part Based on Life Cycle Information, 20th CIRP International Conference on Life Cycle Engineering, Singapore, pp. 337-342 (2013)

7. Fukunaga, Y., Yokoki, Y., Hiraoka, H.: Bayesian network for the reuse of mechanical parts using part agents. 2016 JSPE Autumn Meeting, Ibaraki, G63, (2016) (in Japanese)

8. Fukumashi, Y., Hiraoka, H.,: Parts exchange using part agents - Development of the experimental system-. EcoDesign Products \& Service (EcoDePS) Symposium 2016, 3-4 (2016) (in Japanese)

9. Nagasawa, A., Hiraoka, H.: Part agent's support for disassembly of mechanical product. 16th International Conference on Precision Engineering, Hamamatsu, Japan, (2016) 